nghiện chích ma túy tại khu vực nông thôn miên núi tỉnh Bắc Giang, năm 2010. Tạp chí Y học thực hành2010, số 742-743: 197-200

3. Nguyễn Thị Dụ, Định hướng chung chẩn đoán và xứ trí ngộ độc cấp, Tư vấn chẩn đoán và xử trí nhanh ngộ độc cấp. Nhà xuất bản Y học Hà Nội. 2004; 9-2 2

4. Gainza I., Nogue S., Martinez Velasco C.,et al (2003), "Drug poisoning", An Sist Sanit Navar, 26 (1): $99-128$

5. Spiller H. A., Hays H. L., Aleguas A. (2013), "Overdose of drugs for attention-deficit hyperactivity disorder: clinical presentation, mechanisms of toxicity, and management", CNS Drugs, 27(7), tr. 531-43.

6. Fogel C Osborne GB (2008), "Understanding the motivations for recreational marijuana use among adult Canadians", Substance Use \& Misuse,43(3-4), 539-72.

7. Robert J Hoffman (2020), "Ketamine poisoning", Uptodate 2020.

8. Geetruida D van Dijken, Renske E Blom, Ronald J Hené, et al (2013), High incidence of mild hyponatraemia in females using ecstasy at a rave party, Nephrol Dial Transplant, 28(9):2277-83.

\title{
MộT Số ĐĂC ĐIỂM LÂM SÀNG, CÂ̂N LÂM SÀNG VÀ KẾT QUẢ CHỤP ĐộNG MACH VÀNH QUA DA Ở BỆNH NHÂN NHỒI MÁU CO' TIM CẤP
}

\section{TÓM TẮT}

Nhồi máu cơ tim cấp là một cấp cứu nội khoa với nhiều biến chứng năng như sốc tim, rối loan nhip tim. Chụp động mạch vành qua da là biện pháp để xác đinh vị trí, mức đô tổn thương động mach vành đồng thời can thiệp tái thông động mạch vành. Mục tiêu: Mô tả đặc điểm lâm sàng, cận lâm sàng và kết quả chụp mạch vành qua da ở bệnh nhân nhồi máu cơ tim cấp tại Bệnh viện hữu nghị Đa khoa Nghệ An. Đối tượng và phường pháp nghiên cứu: Nghiên cứu mô tả cắt ngang được thực hiên trên 62 bênh nhân nhồi máu cơ tim cấp điều trị tại Bệnh viện hữu nghị đa khoa Nghê An. Kết quả: Tuổi trung bình là $72,5 \pm$ 12,1 tuổi, nam giới chiếm $70,79 \%$. Đa số bệnh nhân có một hoặc nhiêuu yếu tố nguy cơ đi kèm: tăng huyết áp $(51,61 \%)$, rối loạn lipid máu $(25,80 \%)$, hút thuốc lá $(24,90 \%)$, đái tháo đường $(22,50 \%)$, lạm dụng rượu (4,84\%). Thời gian từ lúc đau ngực đến lúc nhập viện: trước 12 giờ là $58,06 \%$, trước 24 giờ là $67,74 \%$, sau 24 giờ 32,26\%. Tỷ lệ hẹp một động mạch vành là $41,93 \%$, hai động mạch vành là $45,16 \%$, hẹp ba động mach vành là $11,91 \%$. Trong đó, $75,81 \%$ có hep LAD, $56,45 \%$ có hẹp RCA, 43,55\% có hẹp LCX và $1,61 \%$ có hep đông mach phân giác. Kết luân: Đa số bênh nhân nhồi máu cơ tim cấp có một hoặc nhiều yếu tỗ nguy cơ tim mạch đi kèm. Tỷ lệ bệnh nhân đến bệnh viện có khả năng can thiệp mạch sau 24 giờ kể từ khi đau ngực còn cao $(32,26 \%)$. Tỷ lệ hẹp một động mạch vành là $41,93 \%$, hai động mạch vành là $45,16 \%$, hẹp ba động mạch vành là $11,91 \%$ và đa số là hẹp độ 4 và độ 5 .

Tư khóa: Nhồi máu cơ tim cấp, chụp động mạch vành qua da

${ }^{1}$ Trường Đại học Y khoa Vinh,

${ }^{2}$ Bệnh viện Hữu nghị đa khoa Nghệ An

Chịu trách nhiệm chính: Nguyễn Văn Tuấn

Email: tuanminh1975@gmail.com

Ngày nhận bài: 2.3.2021

Ngày phản biên khoa học: 22.4.2021

Ngày duyệt bài: 4.5.2021
Nguyễn Văn Tuấn ${ }^{1}$, Phạm Hồng Phương²

\section{SUMMARY}

THE CLINICAL, SUBCLINICAL FEATURES AND RESULTS OF PERCUTANEOUS ANGIOGRAPHY IN PATIENTS WITH MYOCARDIAL INFARTION AT THE NGHE AN GENERAL HOSPITAL

Acute myocardial infarction is a medical emergency with serious complications such as cardiogenic shock and arrhythmia. Percutaneous coronary angiography is a measure to determine the location and extent of coronary artery damage and interventions to re-open coronary arteries. Objectives: To describe the clinical and subclinical features and the results of percutaneous coronary angiography in patients with acute myocardial infarction at the Nghe An General Hospital. Results: The average age was $72.5 \pm 12.1$ years, and male accounted for $70.79 \%$. The majority of patients had one or more associated risk factors: hypertension $(51.61 \%)$, dyslipidemia $(25.80 \%)$, smoking $(24.90 \%)$, diabetes ( $22.50 \%$ ), abuse of alcohol (4.84\%). The time from chest pain to hospital admission: before 12 hours was $58.06 \%$, before 24 hours was $67.74 \%$, and after 24 hours was $32.26 \%$. The rate of the stenosis of one coronary arteries is $41.93 \%$, the stenosis of two coronary arteries is $45.16 \%$, the stenosis of three coronary arteries is $11.91 \%$. Of which, $75.81 \%$ had LAD stenosis, $56.45 \%$ had RCA stenosis, $43.55 \%$ had LCX stenosis. Conclusion: Most people with acute myocardial infarction have one or more associated cardiovascular risk factors. The proportion of patients going to the hospital that is capable of performing vascular intervention after 24 hours since chest pain remains high $(32,26 \%)$. The rate of one coronary stenosis is $41,93 \%$, two coronary stenosis is $45,16 \%$, three coronary stenosis is $11,91 \%$ and the majority is grade 4 and 5 stenosis.

Keywords: Acute myocardial infarction, percutaneous coronary angiography

I. ĐĂT VẤN ĐỀ

Nhồi máu cơ tim (NMCT) là một cấp cứu nội 
khoa nặng với nhiều biến chứng nguy hiểm nhứ sốc tim, rối loạn nhịp tim với tỷ lệ tử vong cao. Ở Việt Nam tình hình nhôi máu cơ tim có xu hương gia tăng. Mặc dù hiện nay đã có nhiêuu tiến bộ trong chẩn đoán và điêu trị nhưng tỷ lệ tử vong do nhồi máu cơ tim còn khá cao. Hiện nay tiêu huyết khối và can thiệp động mạch vành (ĐMV) qua da là biện pháp chính trong điêu trị nhồi máu cơ tim cấp. Can thiệp động mạch vành qua da đã chứng tỏ được ưu thế trong điều trị NMCT cấp như giảm tỷ lệ tử vong, thông được chỗ tắc nghẽn động mạch vành mà còn giải quyết được các hẹp ĐMV tồn dư bằng các biện pháp cơ học. Tuy nhiên, kết quả của can thiệp ĐMV còn phù thuộc vào nhiêu yếu tố như thời gian tiếp cận với nhân viên y tế, thời gian vận chuyển bệnh nhân cũng như tình trạng bệnh nhân cụ thể. Nghệ An là một tỉnh đông dân cư, địa bàn rộng và có địa hình phức tạp nên bệnh nhân ở một số vùng xa trung tâm thì thời gian từ khi bị NMCT đến khi tiếp cận với đơn vị y tế có khả năng can thiệp mạch vành thường muộn nên ảnh hưởng đến kết quả tái thông động mạch vành. Xuất phát từ vấn đề đó, chúng tôi nghiên cứu đề tài này với mục tiêu: Mô tả đặc điểm lâm sàng, cận lâm sàng và kêt quả chụp mạch vành qua da ở bệnh nhân nhồi máu cơ tim câp tại Bệnh viện hữu nghị Đa khoa Nghệ An.

\section{II. ĐỐI TƯỢNG VÀ PHƯƠNG PHÁP NGHIÊN CỨU \\ 2.1 Đối tượng nghiên cứu}

2.1.1. Tiêu chuẩn lứa chọn. Nghiên cứu tiến hành trên bệnh nhân được chẩn đoán NMCT cấp, có chụp mạch vành qua da điều trị tại khoa Tim mạch, Bệnh viện hữu nghị Đa khoa Nghệ An.

Tiêu chuẩn chẩn đoán NMCT theo Định nghĩa lần thứ ba toàn câu về NMCT của ESC/ACCF/AHA/WHF năm 2012 [8].

2.1.2. Tiêu chuẩn loại trừ. NMCT cũ đến bệnh viện điều trị vì nguyên nhân khác.

Bệnh nhân từ chối tham gia nghiên cứu.

2.2. Địa điểm nghiên cứu: Khoa tim mạch, Bệnh viện Hữu nghị đa khoa Nghệ An.

\subsection{Phương pháp nghiên cứu}

2.3.1. Thiết kế nghiên cứu: Nghiên cứu mô tả cắt ngang

2.3.2. Cõ mẫu và cách chọn mẫu: 62 bệnh nhân nhồi máu cơ tim cấp thõa mãn tiêu chuẩn lựa chọn được đưa vào nghiên cứu.

2.3.3. Kỹ thuật chính sử dụng trong nghiên cứu. Chụp động mạch vành qua da được thực hện trên máy chụp mạch số hóa xóa nền (DSA) Allura FD 10 tại Bệnh viện Hữu nghị đa khoa Nghệ An.

2.4. Xử lý số liệu: - Số liệu được xử lý bằng phân mềm SPSS 20.0.

- Sử dụng ANOVA test để so sánh trung bình các quan sát nếu biến có phân bố chuẩn.

- Sử dụng test X2 để so sánh sự khác biệt về tỷ lệ phân trăm.

\section{KẾT QUẢ NGHIÊN CứU}

\section{1. Đắc điểm lâm sàng và cận lâm sàng} của đối tượng nghiên cứu

Bảng 3.1. Đăc điểm tuôii, giới của các đôí tương nghiên cứu

\begin{tabular}{|c|c|c|}
\hline Đặc điểm & Nam & Nữ \\
\hline Tổng & 44 & 18 \\
\hline Tỉ lệ (\%) & 70,97 & 29,03 \\
\hline Nam/ nữ & \multicolumn{2}{|c|}{$2,44 / 1$} \\
\hline Tuối trung bình & \multicolumn{2}{|c|}{$72,5 \pm 12,1$} \\
\hline
\end{tabular}

Nhận xét: Độ tuối trung bình mắc NMCT là 72,5 $\pm 12,1$ năm. Trong đó, tập trung nhiêuu nhất ở nhóm trên 75 tuổi $(45,16 \%)$. Bệnh gặp chủ yếu ở nam (70,79\%), nữ chiếm 29,03\%, tỷ lệ nam/ nữ là 2,44/1.

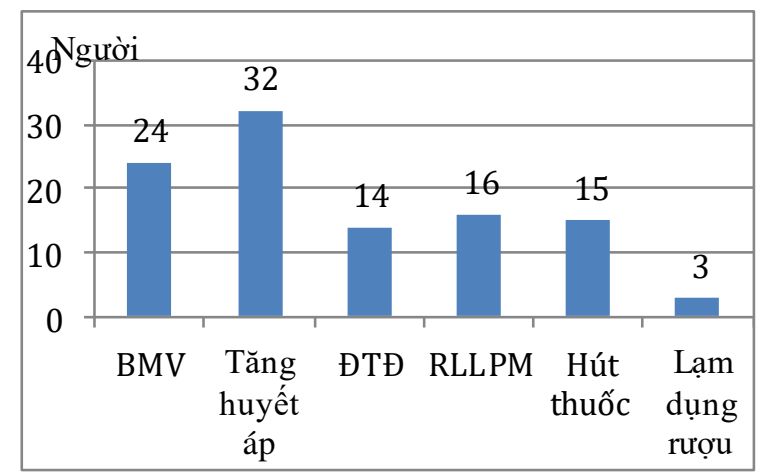

Biểu đồ 3.1 Tỷ lệ mắc các yếu tố nguy cơ của các đôi tượng nghên cứu

Nhận xét: Bệnh tăng huyết áp chiếm tỉ lệ cao nhất $(51,61 \%)$, tiếp theo đến tiền sử mắc bệnh mạch vành $(38,71 \%)$, rối loạn lipid máu $(25,80 \%)$, hút thuốc $(24,19 \%)$, đái tháo đường $(22,50 \%)$, lạm dụng rượu $(4,84 \%)$ có tỷ lệ thấp nhất.

Bảng 3.2. Phân bố thời gian từ lúc đau ngực đến lúc nhập viện, thời gian từ lúc nhập viện đến lúc PCI của các đôî̉ tượng nghiên cứu

\begin{tabular}{|c|c|c|c|c|}
\hline Thời gian & $\begin{array}{c}\text { Từ lúc đau ngức đến } \\
\text { lúc nhập viên }\end{array}$ & $\begin{array}{c}\text { Tỉ lệ̂ } \\
\text { (\%) }\end{array}$ & $\begin{array}{c}\text { Từ lúc nhập } \\
\text { viên đến lúc } \mathbf{P C I}\end{array}$ & $\begin{array}{c}\text { Tỉ lệ } \\
\text { (\%) }\end{array}$ \\
\hline Từ giờ thứ 0 đến giờ 1 & 1 & 1.61 & 6 & 9.67 \\
\hline Sau giờ thứ 1 đến giờ 3 & 9 & 14.52 & 21 & 33.87 \\
\hline Sau giờ thứ 3 đến giờ 6 & 12 & 19.35 & 13 & 20.97 \\
\hline
\end{tabular}




\begin{tabular}{|c|c|c|c|c|}
\hline Sau giờ thứ 6 đến giờ 12 & 14 & 22.58 & 9 & 14.52 \\
\hline Sau giờ thứ 12 đến giờ 24 & 6 & 9.68 & 6 & 9.68 \\
\hline Sau 24 giờ & 20 & 32.26 & 7 & 11,29 \\
\hline
\end{tabular}

Nhận xét: Thời gian đến viện chủ yếu trước 24 giờ 42/62 bệnh nhân (67,74\%). Tỷ lệ bệnh nhân đến trước 1 giờ, trước 3 giờ còn thấp 10/62 bệnh nhân (16,13\%). Thời gian từ lúc nhập viện đến lúc can thiệp mạch vành chủ yễu từ giờ thứ 1 đến giờ thứ 3 chiếm $33,87 \%$.

Bảng 3.3 Các dạng rôi loạn nhịp tim của đôi tượng nghiên cứu

\begin{tabular}{|c|c|c|}
\hline Loại rối loạn nhịp & $\begin{array}{c}\text { Số lượng } \\
(\mathbf{n})\end{array}$ & $\begin{array}{c}\text { Tỉ lệ } \\
\mathbf{( \% )}\end{array}$ \\
\hline Nhịp chậm xoang & 5 & 8,06 \\
\hline Nhịp nhanh xoang & 16 & 25,81 \\
\hline Rung nhĩ & 4 & 6,45 \\
\hline Block nhĩ thất cấp I, II & 6 & 9,68 \\
\hline Block nhĩ thất cấp III & 3 & 4,84 \\
\hline Block nhánh trái & 2 & 3,23 \\
\hline Block nhánh phải & 2 & 3.23 \\
\hline
\end{tabular}

Nhận xét: Tỷ lệ bệnh nhân có rối loạn nhip là $38.71 \%$. Trong đó, nhịp nhanh xoang là rối loạn nhịp gặp nhiêu nhất $(25,81 \%)$. Nhịp chậm xoang chiếm tỉ lệ $8,06 \%$, rung nhĩ chiếm $6,45 \%$, block nhĩ thất cấp I, II chiếm 9,68\%, block nhĩ thất cấp 3 chiếm $4,84 \%$, block nhánh trái $3,23 \%$, block nhánh phải 3,23\%.

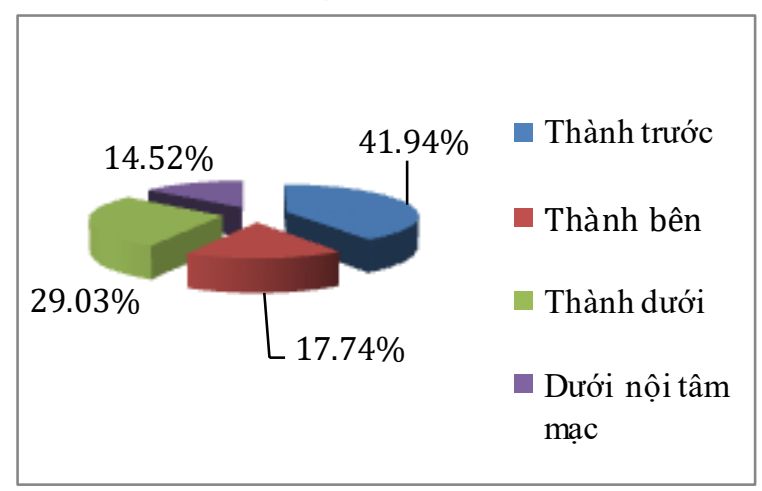

Biểu đồ 3.2 Phân bố vị trí nhồi máu của đôî

tượng nghiên cứu theo điện tâm đồ

Nhận xét: Tỷ lệ bệnh nhân NMCT có ST chênh trên điện tâm đồ lúc nhập viện là $55 / 62$ BN $(88,7 \%)$. Vị trí nhồi máu thành trước chiếm tỷ lệ cao nhất 26/62 bệnh nhân (41,94\%).

3.2. Kết quả chụp động mạch vành qua da của đối tượng nghiên cứu

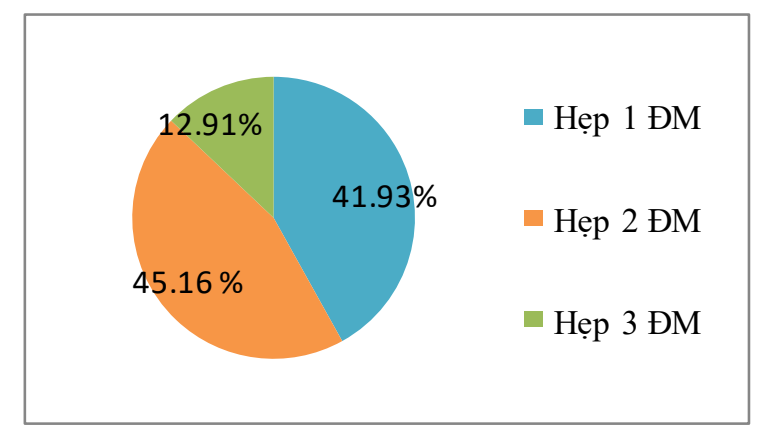

Biểu đồ 3.3 Số động mạch hẹp qua kêt quả

Nhận xét: Số trường hợp hẹp hai động mạch chiếm tỷ lệ cao nhất $28 / 62$ bệnh nhân (45,16\%), hẹp một thân chiếm 26/62 bệnh nhân $(41,93 \%)$, còn lại hẹp ba thân chiếm 8/62 bệnh nhân (12,91\%).

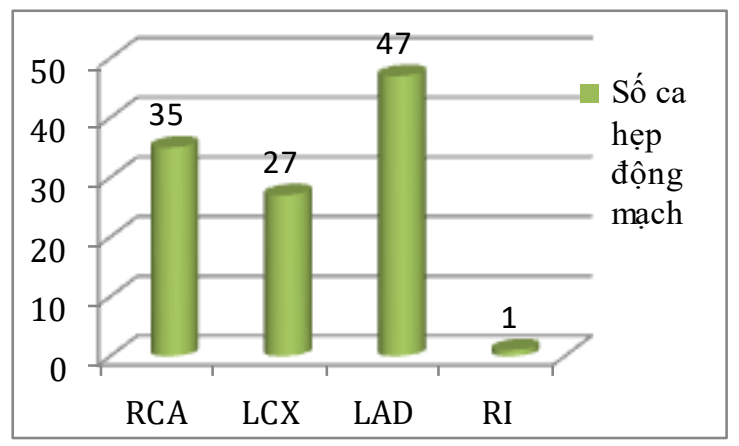

Biểu đồ 3.4. Động mạch vành bị hẹp của đôi tượng nghiên cứu qua chụp ĐMV

Nhân xét: LAD hẹp nhiêu nhất 47/62 bệnh nhân $(75,81 \%)$, RCA chiếm 35/62 bệnh nhân $(56,45 \%)$, LCX gặp trong 27/62 bệnh nhân (43,55\%), động mạch phân giác 1/62 bệnh nhân $(1,61 \%)$.

Bảng 3.4. Mức độ tồn thương ĐMV của đối tượng nghiên cứu

\begin{tabular}{|c|c|c|c|c|c|}
\hline ĐM Độ hẹp & Độ 1 & Độ 2 & Độ 3 & Độ 4 & Độ 5 \\
\hline ĐMV phải & $1(2,8 \%)$ & $3(8,57 \%)$ & $11(17,74 \%)$ & $12(34,28 \%)$ & $8(22,86 \%)$ \\
\hline Động mạch mũ & 0 & $3(11,12 \%)$ & $3(11,12 \%)$ & $16(59,26 \%)$ & $5(18,51 \%)$ \\
\hline ĐMLTT & $1(2,27 \%)$ & $1(2,27 \%)$ & $5(10,64 \%)$ & $18(38,29 \%)$ & $19(40,43 \%)$ \\
\hline Động mạch phân giác & & & & & $1(100 \%)$ \\
\hline
\end{tabular}

Nhận xét: Đa số động mạch vành bị tốn thương là hẹp độ 4 và độ 5. 


\section{BÀN LUẬN}

4.1. Đặc điểm lâm sàng và cận lâm sàng của đối tượng nghiên cứu

4.1.1. Đặc điểm tuổi, giới tính. Nghiên cứu cho thấy độ tuổi trung bình mắc NMCT là $72,5 \pm$ 12,1 năm. Trong đó tập trung nhiều nhất ở nhóm trên 75 tuổi. Bệnh gặp chủ yếu ở nam 70,79\%, nữ chiếm 29,03\%, tỷ lệ nam/ nữ là 2,44/1.

Kết quả này tương tự với những nghiên cứu trước đây. Trong nghiên cứu của Hà Văn Chiến, tuổi trung bình $67,82 \pm 12,04$ năm, nam chiếm $71,57 \%$, nữ chiếm $28,43 \%$, tỷ lệ nam/nũ là $2,5 / 1$ [1]. Tỷ lệ nam/nữ trong nghiển cứu của Lê Thị Thanh Hằng là 2/1 [3]. Nghiên cứu của tác giả Patrick T.O'Gara có tuổi trung bình là 67,57 $\pm 11,35$ năm, tỷ lệ nam/nữ là 1,37/1 [6].

4.1.2. Đặc điểm các yếu tố nguy cơ. Trong nghiên cứu này, tăng huyết áp chiếm tỉ lệ cao nhất trong các yếu tố nguy cơ tim mạch $(51,61 \%)$. Qua đó thêm khẳng định tăng huyết áp là môt nguy cơ lớn đối với bệnh NMCT. Tiếp theo đến tiền sử mắc bệnh mạch vành $(38,71 \%)$, rối loạn lipid máu $(25,80 \%)$, hút thuốc $(24,19 \%)$, đái tháo đường $(22,50 \%)$ chiếm tỷ lệ cao, lạm dụng rượu có tỳ lệ thấp nhất $(4,84 \%)$. Huyết áp, rối loạn lipid máu, đái tháo đường, hút thuốc lá là các yếu tố nguy cơ tim mạch chính [2]. Một nghiên cứu của Hani Jneid cho thấy $90 \%$ bệnh nhân bị NMCT có một trong ba nguy cơ chính là tăng huyết áp, rối loạn lipid máu và hút thuốc lá [7].

Những nghiên cứu các tác giả trong và ngoài nước cho kết quả tương tự. Nghiên cứu Lê Thị Thanh Hằng tỷ lệ THA là 68,9\% [3]; Nguyễn Quang Tuấn tỷ lệ THA 45,6\%, hút thuốc lá là $38,6 \%$, đái tháo đường là $28,9 \%$, béo phì là $21,9 \%$; Hani Jneid tỷ lệ THA là 55,34\%, rối loạn lipid máu là 30,43\%, hút thuốc lá là 29,73\% [7].

4.1.3. Đặc điểm thời gian từ lúc đau ngực đến lúc nhập viện, thời gian từ lúc nhẩp viện đến lúc can thiệp mạch vành. Thời gian đến viện từ giờ thứ 6 đến giờ thứ 12 chiếm tỷ lệ cao nhất $22,58 \%$, từ giờ thứ 3 đến giờ thứ 6 chiếm $19,35 \%$. Tổng số bênh nhân đến trước 24 giờ chiếm 67,74\%. Bệnh nhân đến sau 24 giờ chiếm 32,25\%. Tỷ lệ bệnh nhân đến trước 1 giờ, trước 3 giờ còn thấp $10 / 62$ bệnh nhân $(16,13 \%)$. Điều này cho thấy bệnh nhân còn kéo dài thời gian đến viện, rất ít bệnh nhân đến viện được trong khung giờ tái thông mạch máu tốt nhất.

Kết quả này cũng tương tự nghiên cứu của Hà Văn Chiến: trước 6 giờ có $26 / 102$ bệnh nhân (25,49\%), từ 6-12 giờ có $16 / 102$ bệnh nhân
(15,69\%), từ 12-24 giờ: 27/102 bệnh nhân (26,47\%), tỷ lệ nhập viện trước 24 giờ là 69/102 bệnh nhân $(67,65 \%)$, sau 24 giờ là 33/102 bệnh nhân $(32,35 \%)$ [1].

4.1.4. Đặc điểm điện tâm đồ của đối tượng nghiển cứu. Tỷ lệ bệnh nhân NMCT có ST chênh trên điện tâm đồ lúc nhập viện của mẫu nghiên cứu chung là 55/62 BN $(88,7 \%)$, còn lại $7 / 162$ BN $(11,3 \%)$ bênh nhân NMCT dưới nội tầm mạc. Kết quả nghiên cứu của tác giả Trương Hoàng Anh Thư (2006) tỷ lệ bệnh nhân NMCT cấp ST chênh chiếm $87,8 \%$ và NMCT cấp ST không chênh chiếm 12,2\% [5].

Vùng nhồi máu trên ECG: Thành trước chiếm tỷ lệ cao nhất $26 / 62$ bệnh nhân $(41,94 \%)$, tiếp theo là thành dưới $18 / 62$ bênh nhân $(29,03 \%)$. Thành bên chiếm tỷ lệ thấp nhất $11 / 62$ bệnh nhân (17,74\%).

So sánh với các kết quả nghiên cứu khác:

Bảng 4.1 Các kêt quả nghiên cứu vùng nhồi máu cơ tim

\begin{tabular}{|c|c|c|}
\hline Tác giả & $\begin{array}{c}\text { Thành } \\
\text { trước (\%) }\end{array}$ & $\begin{array}{c}\text { Thành } \\
\text { dưới (\%) }\end{array}$ \\
\hline Hà Văn Chiến & 40,19 & 45,09 \\
\hline Nguyên Văn Tân & 65 & 46,3 \\
\hline Marisa $\mathrm{FL} \mathrm{(2002)}$ & 41,6 & 41 \\
\hline Dang AD (2008) & 63,3 & 32,9 \\
\hline
\end{tabular}

Về các rối loạn nhịp tim kèm theo, tỷ lê bênh nhân có rối loạn nhịp là $38.71 \%$. Trong đó, nhịp nhanh xoang là rối loạn nhịp gặp nhiêu nhất $25,81 \%$, tiếp theo là block nhĩ thất (14,52\%). Các dạng rối loạn nhịp block nhanh phải $(3,22 \%)$, block nhánh trái $(3,22 \%)$,block nhĩ thất cấp III chiếm 4,84\%, rung nhĩ $(6,45 \%)$, nhịp chậm xoang $(8,06 \%)$ chiếm tỷ lệ ít hơn.

4.2. Kết quả chụp động mạch vành qua da của đối tượng nghiên cứu

Tỷ lệ hẹp một động mạch vành là 41,93\%, hai động mạch vành là $45,16 \%$, hẹp ba động mạch vành là $11,91 \%$. Trong đó LAD hẹp nhiều nhất với 47/62 bệnh nhân (75,81\%), RCA chiếm $35 / 62$ bệnh nhân $(56,45 \%)$ và LCX gặp trong $27 / 62$ bệnh nhân (43,55\%). Động mạch phân giác $1 / 62$ bệnh nhân $(1,61 \%)$.

So sánh với kết quả của Phạm Văn Hùng cũng cho tỷ lệ tương tự: hẹp LAD 46,3\%, RCA $35,9 \%$, LCX $17,8 \%$ [4].

Mức độ hẹp chủ yếu là độ 4 (LAD 14/35 bệnh nhân, RCA 16/27 bệnh nhẩn, LCX 18/47 bệnh nhân), độ 5 (LAD 8/35 bệnh nhân, RCA 5/27 bệnh nhẩn, LCX 19/47 bệnh nhân, động mạch phân giác $1 / 1$ bệnh nhân).

So sánh kết quả chụp ĐMV và điện tâm đô ta thấy: Trong thành dưới, động mạch thủ 
phạm chiếm tỷ lệ cao nhất là RCA $(55,56 \%)$, LCX chiếm 16,67\%, LAD chiếm 27,77\%. Tổn thương phối hợp cả ba động mạch chiếm tỷ lệ $61,11 \%$, hai động mạch chiếm tỷ lệ 39,89\%.

Trong thành trước, động mạch thủ phạm chiếm tỷ lệ cao nhất là RCA $(73,08 \%)$, LAD chiếm $27,77 \%$, RI chiếm 3,85\%, không có trường hợp nào do LCX. Tổn thương phối hợp cả ba động mạch chiếm tỷ lệ $42,31 \%$, hai động mạch chiếm tỷ lệ $58,69 \%$.

Trong thành bên, động mạch thủ phạm chiếm tỷ lệ cao nhất là LCX $(54,54 \%)$, LAD chiếm 45,46\%, không có trường hợp nào do RCA. Tổn thương phối hợp cả ba động mạch chiếm tỷ lệ 42,31\%, hai động mạch chiếm tỳ lệ $58,69 \%$.

\section{KẾT LUÂNN}

- Tuổi trung bình là $72,5 \pm 12,1$ tuổi, nam giới chiếm 70,79\%.

- Đa số bệnh nhân có một hoặc nhiều yếu tố nguy cơ đi kèm: tăng huyết áp $(51,61 \%)$, rối loạn lipid máu $(25,80 \%)$, hút thuốc lá $(24,90 \%)$, đái tháo đường $(22,50 \%)$, lạm dụng rượu $(4,84 \%)$.

- Thời gian từ lúc đau ngực đến lúc nhập viện: trước 12 giờ là $58,06 \%$, trước 24 giờ là $67,74 \%$, sau 24 giờ $32,26 \%$.

- Tỷ lệ hẹp một động mạch vành là 41,93\%, hai động mạch vành là $45,16 \%$, hẹp ba động mạch vành là $11,91 \%$. Trong đó, $75,81 \%$ có hẹp
LAD, 56,45\% có hẹp RCA, 43,55\% có hẹp LCX và $1,61 \%$ có hẹp động mạch phân giác.

\section{TÀI LIÊU THAM KHẢO}

1. Hà Văn Chiến (2017), Nghiên cứu đặc điểm lâm sàng và cận lâm sàng của bệnh nhân nhồi máu cơ tim cấp điều trị tại bệnh viện tỉnh Thanh Hóa, Luận văn thac sỹ Y học: Đại hoc Y khoa Hà Nội.

2. Ngô Quý Châu, Nguyến Lân Việt (2016), Nhồi máu cơ tim cấp. Bệnh học Nội khoa. Tập 1: Nhà xuất bản $Y$ học.

3. Lê Thị Thanh Hằng (2010), Nghiên cứu đặc điểm lẩm sàng và cận lâm sàng và các yếu tố ngưy cơ của nhồi máu cơ tim cấp ở nữ giới, in Luận án Tiến sĩ Y hoc: Hoc viện Ouân Y.

4. Phạm Văn Hùng (2018), Đánh giá kết quả chụp và can thiệp động mạch vành qua da tại bệnh viện Đà Năng. Tạp chí Tim mạch học Việt Nam, 80: p. 11-12.

5. Trương Hoàng Anh Thư (2006), Khảo sát tình hình theo dõi và điều tri bệnh nhân sau nhồi máu cơ tim cấp tại Bệnh viện Nguyễn Tri Phương từ năm 2003 - 2005. Tap chí Y học, 2006: p. 45-50.

6. Patrick, T.O.G. (2013), 2013 ACCF/AHA Guideline for the Management of ST-Elevation Myocardial Infarction, R.o.t.A.C.o.C. Foundation, p. 144-164.

7. Jneid, H. (2012), 2012 ACCF/AHA Focussed Update of The Guidelines for the management of patients with unstable angina/non-ST-elevation myocardial Infartion. report of the American College of Cardiology Foundation. 60: p. 645-681.

8. Stephan D. Fihn, Julius M. Gardin, Jonathan Abrams (2012), 2012 ACCF/AHA/ACP/AATS/ PCNA/SCAI/STS Guideline for the Diagnosis and Management of Patients With Stable Ischemic Heart Disease. Circulation. 126: p. 354-471.

\section{ĐIỀU TRI SA MỎM CẮT ÂM ĐẠO BẰNG PHƯƠNG PHÁP ĐĂT VÒNG NÂNG TRỀN CA LÂM SÀNG TẠI BỆnH VIÊ̂N PHỤ SẢN THÀNH PHỐ CẦN THO'}

\section{TÓM TẮT}

Sa vòm âm đạo hay mỏm cắt âm đạo sau cắt tử cung là sự tụt xuổng của đỉnh âm đạo sau phẫu thuật cắt tử cung. Sa móm cắt âm đạo sau cắt tử cung là một biến chứng hiếm gặp sau phẫu thuật cắt tử cung cả đường bụng và đường âm đạo. Nguy cơ sa mỏm cắt tăng lên khi cắt tử cung qua đường âm đao. Tỷ lê sa mỏm cắt âm đạo là $11,6 \%$ sau khi cắt tử cung vì bệnh lý sa tang chẩu và $1,8 \%$ cho bênh lý khác của tử cung [4]. Ngày nay, có nhiêu phương pháp để điều trị

*Đại hoc Y Dượ TP.HCM

Chịu trách nhiệm chính: Lý Kim Ngân

Email: drlkngan@gmail.com

Ngày nhận bài: 5.3.2021

Ngày phản biện khoa học: 27.4 .2021

Ngày duyệt bài: 7.5.2021

\section{Lý Kim Ngân*, Võ Minh Tuấn*}

sa mỏm cắt âm đạo như phẫu thuật, tập cơ sàn chậu, đặt vòng nâng. Trong đó, phấu thuật là một can thiệp hiệu quả cho những phụ nữ bị sa mỏm cắt âm đạo sau cắt tử cung. Nhưng đối với bệnh nhân già yếu, có nhiều bệnh lý đi kèm thì đặt vòng nâng vân là một lựa chọn điểu trị bảo tồn có thể được cân nhắc như điểu trị đầu tay. Tỷ lệ thành công với đặt vòng nâng điều trị sa tạng chậu sau cắt tử cung là $63,2 \%$ [3]. Cho thấy tỷ lệ thất bại sau đặt vòng nâng là khá cao. Một trong những yếu tố tiên lượng khả năng đặt vòng thất bại là đã phâu thuật cắt tử cung. Tuy nhiên, chúng tôi giới thiệu một trường hợp điều trị sa mỏm cắt âm đạo thành công bằng phương pháp đă̆t vòng nâng, với chất lượng cuộc sônng tăng mạnh. Bệnh nhân 73 tuổi, PARA 100010, sa móm cắt âm đạo độ III theo POP-Q. Bệnh nhân được đặt vòng nâng Gellihorn $57 \mathrm{~mm}$ điều trì với điểm số PFDI-20 và PFIQ-7 trước đăt vòng nầng là 141.67 và 95.24. Sau 1 tháng theo dõ̃i điểm 